\title{
MicroRNA-182 promotes proliferation and metastasis by targeting FOXF2 in triple-negative breast cancer
}

\author{
XINGZENG ZHANG, GENSHUN MA, JIANCHAO LIU and YAJUN ZHANG \\ Department of General Surgery, Liaocheng People's Hospital, Liaocheng, Shandong 252000, P.R. China
}

Received June 28, 2017; Accepted August 11, 2017

DOI: $10.3892 / 01.2017 .6778$

\begin{abstract}
Triple-negative breast cancer (TNBC), the most aggressive subtype of breastcancer(BC), is characterized as high proliferation, young age and poor prognosis. MicroRNA-182 (miR-182) was reported to have oncogenic potential in many cancers. We aimed to elucidate pathobiological effects of miR-182 expression by targeting forkhead-box F2 (FOXF2) in TNBC. In this study, we explored the functional role of miR-182 expression in TNBC. Quantitative real-time PCR (qRT-PCR) was applied to evaluate the expression of miR-182 in cell lines and tissues. A series of in vitro and in vivo assays were performed in the MCF-7 and MDA-MB-231 cell lines with miR-182 overexpression. Luciferase reporter assays and western blot analysis were used to identify FOXF2 as the direct and functional target of miR-182. In TNBC tissues and cell lines, we found that miR-182 was significantly upregulated. Transwell assay showed that re-expression of miR-182 increased cell migration and invasion abilities and MTT assay showed that it promoted cell growth in vitro. In vivo assay, re-expression of miR-182 significantly increase tumor volume and enhanced instant metastasis in the lungs of mice. Besides, FOXF2 was identified as a direct and functional target of miR-182. These results indicated that miR-182 plays an important role in the initiation and progression of TNBC by targeting FOXF2 and the miR-182/FOXF2 axis may present a new therapeutic strategy for TNBC in the future.
\end{abstract}

\section{Introduction}

Breast cancer (BC) is one of the most frequent tumors affecting women worldwide, with different metastatic potentials and phenotypes due to inherently different biological characteristics $(1,2)$. The basal-like BC subtype

Correspondence to: Dr Xingzeng Zhang, Department of General Surgery, Liaocheng People's Hospital, 67 Dongchangxi Road, Liaocheng, Shandong 252000, P.R. China

E-mail: xingzengzhang67@163.com

Key words: triple-negative breast cancer, miR-182, proliferation, metastasis, forkhead-box F2 commonly refers to any mammary gland that lacks expression of the progesterone receptor (PR), estrogen receptor (ER), and human epidermal growth factor receptor (HER) 2, which is widely regarded as triple-negative BC (TNBC) (3-5). TNBC is characterized as a mesenchymal phenotype, high proliferation, aggressive clinical behavior and young age accounts for approximately $8-15 \%$ of all BC and (6,7). Recently, researchers have drawn particular attention to TNBC because of its poor unfavorable clinical outcome and lower 5-year survival rate (8). Patients with TNBC are not expected to benefit from endocrine or anti-HER 2 molecularly targeted therapies, which solely relies on chemotherapy $(9,10)$. A better investigation of the molecular regulatory mechanisms could provide effective therapeutic strategies for TNBC treatment.

MicroRNAs (mRNAs) are endogenous 21-24 nucleotide single-stranded noncoding RNAs, bind to the 3'-untranslated region (3'UTR) of multiple target mRNAs and have been found to play important roles in tumorigenesis and progression (11-14). Numerous miRNAs have been proved to be encoded in cancer-related gene regions, revealing that alteration of miRNA expression may have a causal relationship with tumorigenesis $(15,16)$. Furthermore, the oncogenic properties of miR-182 in various tumors have been elucidated (17). Previous studies demonstrated miR-182 clould regulate many suppressor genes in BC, including BRCA1 (18), RECK (19), PFN1 (8), FOXO1 (20), ZEB1 and HSF2 (21).

The mesenchymal regulator forkhead-box (FOX)F2 belongs to the FOX transcription factor superfamily, which is characterized by tissue homeostasis through regulating epithelial-mesenchymal interaction to maintain epithelium polarity (22) and regulate various biological processes (23). Recent studies indicated that FOXF2 was a tumor suppressor in prostate cancer (24). Wang et al reported deficiency of FOXF2 could induce the metastasis of basal-like BC cells by activating epithelial-mesenchymal transition (EMT) program (25). However, the pathobiological effects of miR-182 expression by targeting FOXF2 in TNBC have not been fully elucidated.

In the present study, we found that miR-182 was aberrantly upregulated in TNBC cells and tissues and miR-182 promoted TNBC cell proliferation and metastasis. Furthermore, FOXF2 was identified as a functional and direct target of miR-182. Therefore, this study is expected to present fruitful strategies of tumor suppressor miR-182 as a potential target for TNBC therapy. 
Table I. Clinicopathological parameters of TNBC patients (total cases, $n=55$ ).

\begin{tabular}{|c|c|c|c|c|}
\hline \multirow[b]{2}{*}{ Characteristics } & \multirow[b]{2}{*}{ Cases } & \multicolumn{2}{|c|}{ miR-182 expression } & \multirow[b]{2}{*}{ P-value } \\
\hline & & Low, n (\%) & High, n (\%) & \\
\hline Age (years) & & & & 0.7048 \\
\hline$\leq 40$ & 9 & $2(22.22)$ & $7(77.78)$ & \\
\hline$>40$ & 46 & $15(32.61)$ & 31 (67.39) & \\
\hline Tumor size $(\mathrm{cm})$ & & & & 0.7230 \\
\hline$<2$ & 10 & $3(30.00)$ & $7(70.00)$ & \\
\hline$\geq 2$ & 45 & $19(42.22)$ & $26(57.78)$ & \\
\hline Lymph node metastases & & & & 0.0431 \\
\hline 0 & 3 & $1(33.33)$ & $2(66.67)$ & \\
\hline $1-3$ & 10 & $5(50.00)$ & $5(50.00)$ & \\
\hline$>3$ & 42 & $6(14.29)$ & $36(85.71)$ & \\
\hline Differentiation & & & & 0.2788 \\
\hline Well & 5 & $2(40.00)$ & $3(60.00)$ & \\
\hline Moderate & 10 & $5(50.00)$ & $5(50.00)$ & \\
\hline Poor & 40 & $12(30.00)$ & $28(70.00)$ & \\
\hline Tumor stage & & & & 0.0216 \\
\hline $\mathrm{I}+\mathrm{II}$ & 16 & $7(43.75)$ & $9(56.25)$ & \\
\hline III+IV & 39 & $5(12.82)$ & $34(87.18)$ & \\
\hline
\end{tabular}

TNBC, triple-negative breast cancer.

\section{Materials and methods}

Patients and specimens. The TNBC tissues and adjacent relatively normal tissues were collected in Liaocheng People's Hospital from May 2009 to August 2014. None of the patients had chemotherapy or other treatment history previously and the TNBC patients were not afflicted with other inflammatory diseases. Surgically resected TNBC tissue and adjacent relatively normal breast tissue were immediately immersed in RNAlater (Ambion; Thermo Fisher Scientific, Inc., Waltham, MA, USA) and stored at $-80^{\circ} \mathrm{C}$. This study was approved by the Ethics Committee of Liaocheng People's Hospital, in accordance with the Helsinki Declaration of 1975 and written informed consent was given by all participants. The clinical characteristics are shown in Table I.

Cell culture and miR-182 transfection. TNBC cell lines MCF-7, MDA-MB-231 and non-tumorigenic mammary epithelial cell MCF-10A were obtained from the American Type Culture Collection (Manassas, VA, USA). Cells were cultured in cell culture medium consisting of 1:1 Medium199 and MCDB105 medium (both from Sigma-Aldrich; Merck KGaA, Darmstadt, Germany) with $10 \%$ heat-inactivated fetal bovine serum (FBS; Gibco; Thermo Fisher Scientific, Inc., Waltham, MA, USA) and $10 \mathrm{ng} / \mathrm{ml}$ epidermal growth factor (Sigma-Aldrich; Merck KGaA). For stable infection, MDA-MB-231 cells were evenly seeded in 6-well plates (Corning Incorporated, Corning, NY, USA) at a concentration of $3 \times 10^{5}$ cells $/ \mathrm{ml}$. After the cells adhered, the transfection of the miR-182 mimics, miR-182 inhibitor and negative control were performed with
Lipofectamine $^{\text {TM }} 2000$ (Invitrogen Life Technologies; Thermo Fisher Scientific, Inc., Waltham, MA, USA) according to the manufacturer's protocol, which clould achieve the ectopic expression of miRNA. The transfection protocol for siRNA was the same as that for miR-182 mimics/inhibitor. miR-182 mimics/inhibitor and FOXF2-siRNA were purchased from Guangzhou RiboBio Co., Ltd. (Guangzhou, China).

RNA isolation and $q P C R$. Total RNA was extracted using the TRIzol reagents (Ambion; Thermo Fisher Scientific, Inc.) from culture cells and cancer tissues according to the manufacturer's instruction. The cDNA were synthesized from total RNA using the miScript reverse transcription kit (Qiagen SA, Courtaboeuf Cedex, France). qRT-PCR was performed using StepOne Plus qPCR System (Applied Biosystems; Thermo Fisher Scientific, Inc., Waltham, MA, USA). All primers used were purchased from Guangzhou RiboBio Co., Ltd. The following cycling conditions were employed for qPCR: $95^{\circ} \mathrm{C}$ for $10 \mathrm{~min}$, followed by 40 cycles of $95^{\circ} \mathrm{C}$ for $10 \mathrm{sec}$ and $60^{\circ} \mathrm{C}$ for $1 \mathrm{~min}$. The level of mature miR-182 was normalized relative to U6 endogenous control and FOXF2 expression was normalized relative to $\beta$-actin (endogenous control) using the $2^{-\Delta \Delta \mathrm{Cq}}$ method.

MTT assay. For proliferation rate, cells were uniformly seeded onto 96-well plates at a density of $5 \times 10^{3}$ cells per well. After reaction with $20 \mu 15 \mathrm{mg} / \mathrm{ml}$ sterile MTT (Sigma-Aldrich; Merck KGaA) for $4 \mathrm{~h}$ at $37^{\circ} \mathrm{C}$, culture media was removed and $100 \mu \mathrm{l}$ of dimethyl sulphoxide (DMSO; Sigma-Aldrich; Merck $\mathrm{KGaA}$ ) was added to each well. The absorbance values were 
A

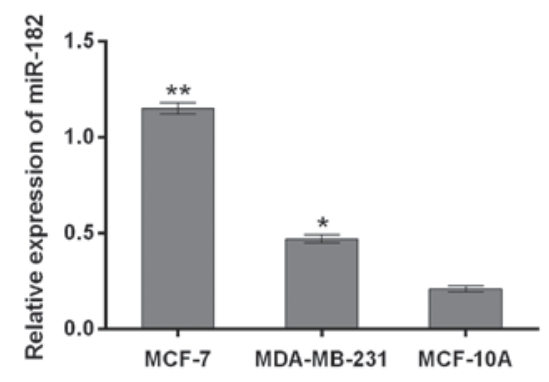

C

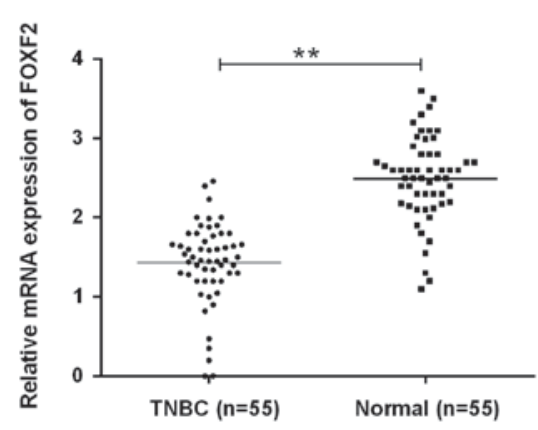

B

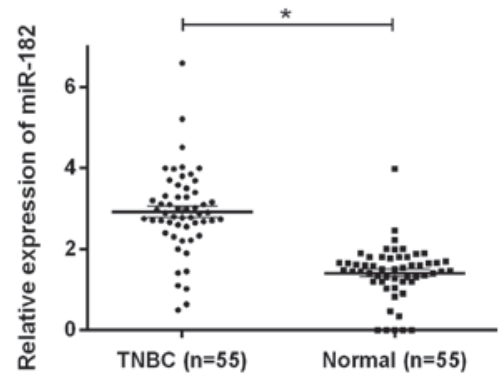

D

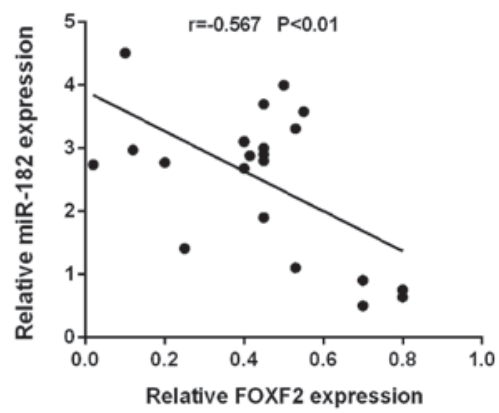

Figure 1. Upregulation of miR-182 in TNBC tissues and cell lines inversely correlated with FOXF2 expression levels. (A) Relative expression of miR-182 in two BC cell lines and one normal cell line. (B and C) miR-182 and FOXF2 mRNA expression levels in the TNBC tissues compared with adjacent relatively normal breast tissues. (D) Spearman's correlation analysis between miR-182 expression and FOXF2 mRNA level in 22 TNBC tissues ${ }^{*} \mathrm{P}<0.05,{ }^{* * *} \mathrm{P}<0.01$. TNBC, triple-negative breast cancer; FOX, forkhead-box (F2); miR, microRNA; BC, breast cancer.

evaluated at $490 \mathrm{~nm}$ with the ELISA reader (BioTek, Winooski, USA). All the reactions were performed in triplicates.

Migration and invasion assays. After the MCF-7 and MDA-MB-231 cells were transfected with the miR-182 inhibitor and negative control for $24 \mathrm{~h}$, Transwell assay was performed. Briefly $5-10 \times 10^{4}$ cells were seeded into the upper and lower chambers filled with culture medium containing $20 \% \mathrm{FBS}$ as a chemoattractant. The cells were then washed one to two times with PBS and stained with $0.2 \%$ crystal violet. The number of successfully translocated cells was counted under a light microscope.

In vivo nude mouse tumorigenesis and metastasis experiments. All animal experiments were approved by the Liaocheng People's Hospital Animal Care and Use Committee. For xenograft experiment, cells were injected intravenously into $\mathrm{BALB} / \mathrm{c}$ nu/nu female mice aged 4-5 weeks. Upon euthanasia, tumor growth was measured by calculating tumor volume based on the formula: Volume $\left(\mathrm{mm}^{3}\right)=\mathrm{L} \mathrm{x} \mathrm{W}^{2} \times \Pi / 6$ where $\mathrm{L}$ is tumor length and $\mathrm{W}$ is tumor width. After 28 days (MDA-MB-435s cells), mice were euthanized and lungs were surgically dissected. Histological analysis with hematoxylin and eosin was carried out as described previously (26).

Western blot analysis. Cultured cells were collected and lysed with radio immune precipitation assay (RIPA) lysis buffer (Beyotime Institute of Biotechnology, Haimen, China). Protein samples were separated by SDS-PAGE and then transferred to polyvinyl difluoride membrane (EMD Millipore, Billerica, MA, USA). The membranes were incubated in primary antibodies followed by incubation with horseradish peroxidase-coupled secondary antibody (Santa Cruz Biotechnology, Inc., Dallas, TX, USA). All the antibodies were obtained from Abcam (Cambridge, UK). $\beta$-actin was used as internal control. The signals were detected with the ECL western blot analysis system (Amersham; GE Healthcare, Chicago, IL, USA). The protein bands were visualized by autoradiography and quantified by ImageJ software (National Institutes of Health, Bethesda, MD, USA).

Luciferase reporter. The FOXF2 wild- and mutant-type 3'UTR were created and cloned from human genomic DNA. For luciferase assay, cells were seeded on 24-well plates the day before transfection. miR-182 mimic plus WT or MT 3'UTR of FOXF2 were transfected into TNBC cells. After $48 \mathrm{~h}$, the cells were collected and assayed using Dual Luciferase Reporter Assay (Promega Corporation, Madison, WI, USA) according to the manufacture's protocols. Firefly luciferase signal was normalized to Renilla luciferase signal.

Statistical analysis. Data are all presented as means \pm SD in triplicate. Student's t-test was used for comparisons between two groups of experiments. The software SPSS 16.0 (IBM Corp., Armonk, NY, USA) was applied for one-way ANOVA in comparisons among three or more groups. A P $<0.05$ was considered to indicate a statistically significant difference.

\section{Results}

miR-182 expression is upregulated and inversely correlates with FOXF2 in TNBC tissues and cells. We measured miR-182 expression in two TNBC cell lines and one immortalized mammary epithelial cell line MCF-10A. As shown in Fig. 1A, 
A

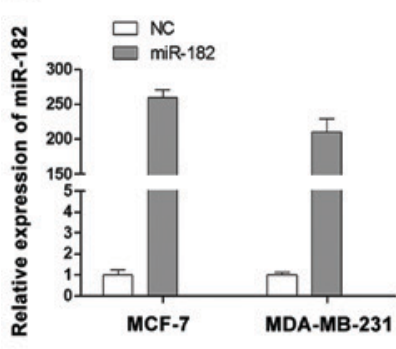

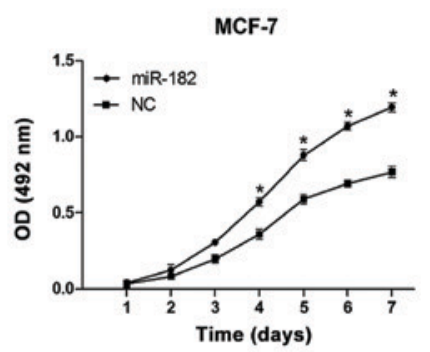

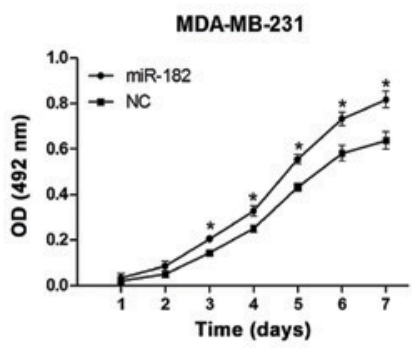

D
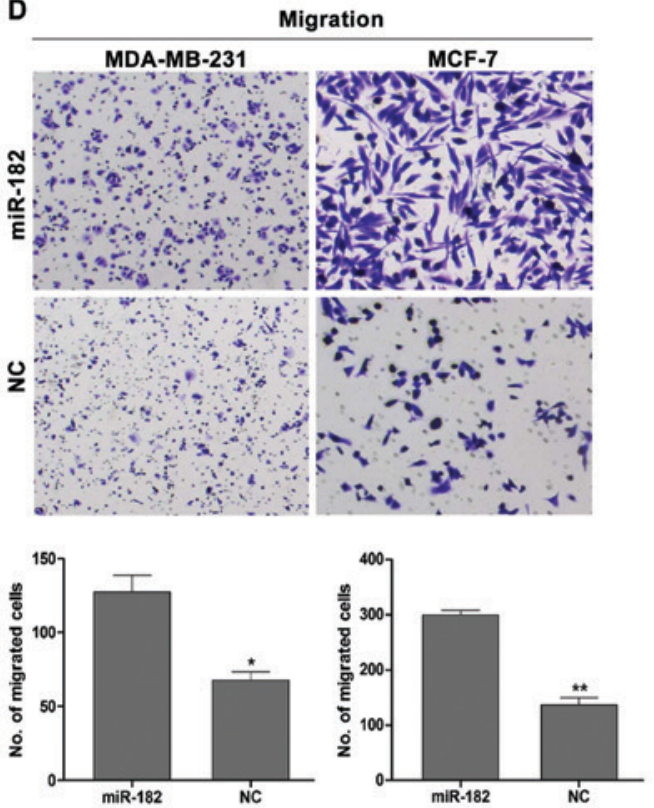
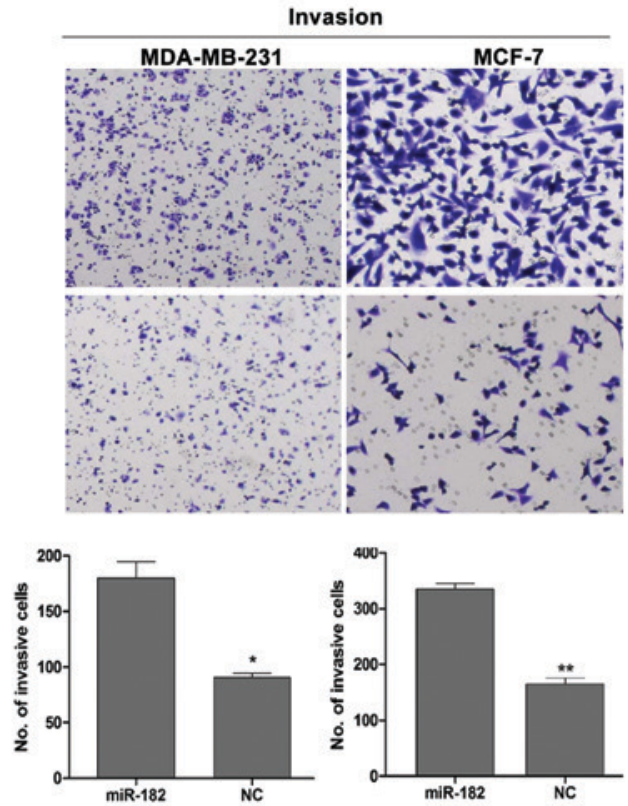

E

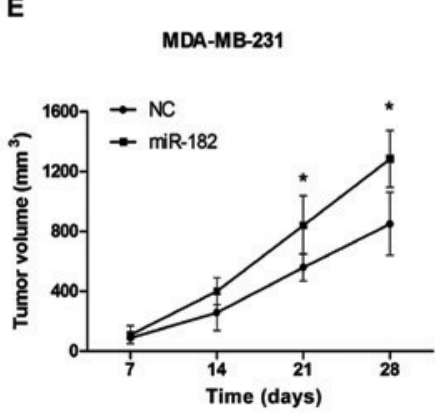

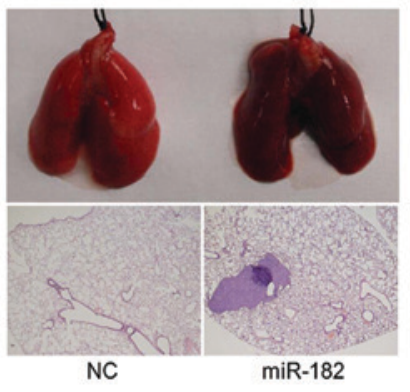

$\mathbf{F}$

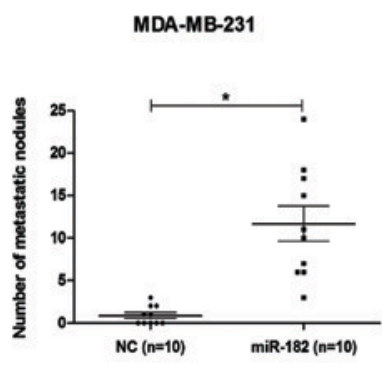

Figure 2. miR-182 overexpression promotes cell proliferation, migration, invasion and metastasis. (A) miR-182 is successfully re-expressed in MCF-7 and MDA-MB-231 cells as confirmed by qPCR. (B and C) Growth curves of miR-182 in MCF-7 and MDA-MB-231 cells mearsured by MTT assay. (D) Effects of ectopic expression of miR-182 on the migration and invasion of MCF-7 and MDA-MB-231 cells. (E) Tumor volume of xenograft mice injected with MDA-MB- 231 cells. (F) Re-expression of miR-182 increased metastasis in vivo. Representative images of the lung sections from mice injected with MDA-MB-231/miR-182 mimic showed more distant metastatic nodules in the lung than that in MDA-MB-231/miR-182 NC cells. "P<0.05, ${ }^{* *} \mathrm{P}<0.01$. miR, microRNA; qRT-PCR, quantitative real-time PCR.

miR-182 expression levels in MCF-7 and MDA-MB-231 cells were significantly higher than those in MCF-10A cells $(\mathrm{P}<0.05)$. To confirm miR-182 upregulation in most TNBC tissues, we examined miR-182 expression in larger clinical samples by qRT-PCR (Fig. 1B). Similar results were obtained that miR-182 was significantly higher in TNBC tissues $(n=65)$ compared with normal samples $(n=65)(P<0.05)$. These findings suggested that miR-182 was upregulated in both TNBC cell lines and tissues. Furthermore, FOXF2 expression levels were measured in TNBC specimens and adjacent normal tissues. qRT-PCR analysis showed significantly lower
mRNA levels of FOXF2 in TNBC, compared with normal tissue (Fig. 1C). Spearman's correlation analysis disclosed an inverse correlation between miR-182 expression and that of FOXF2 (Fig. 1D).

miR-182 promotes proliferation, migration and invasion of TNBC cells in vitro. Given that the miR-182 was upregulated in TNBC cell lines, we next assessed the oncogenic potential of miR-182 in proliferation, migration and invasion by transfection of synthetic miRNA mimics or negative control in vitro. The successful re-expression of miR-182 in TNBC cells was 
A

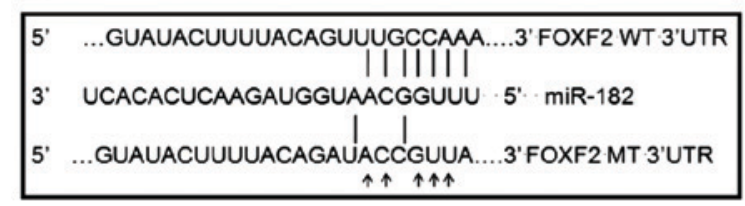

B

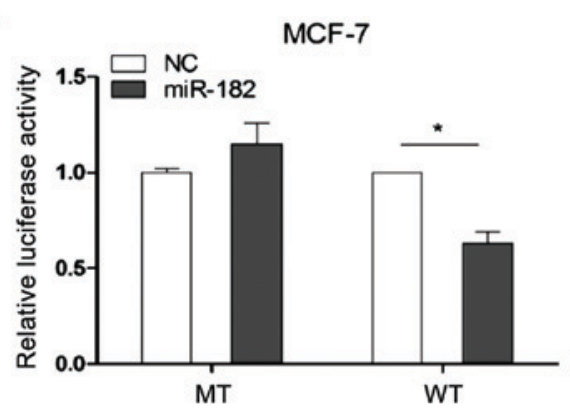

MDA-MB-231

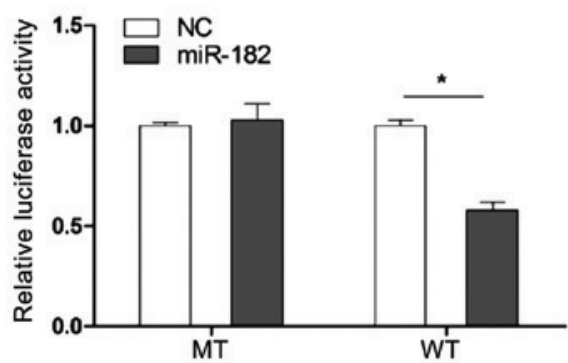

C

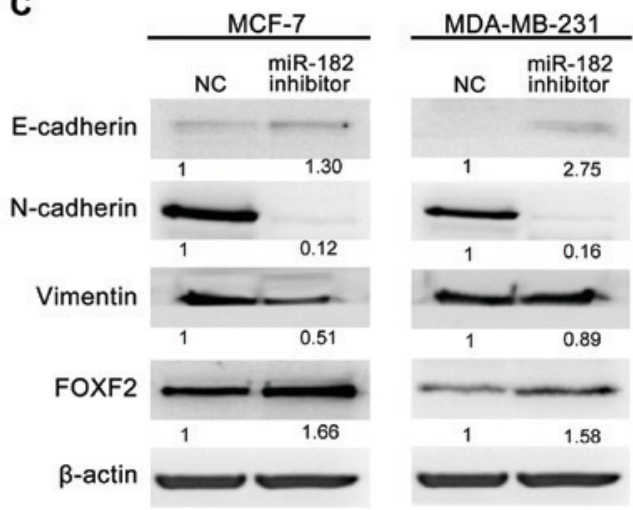

D

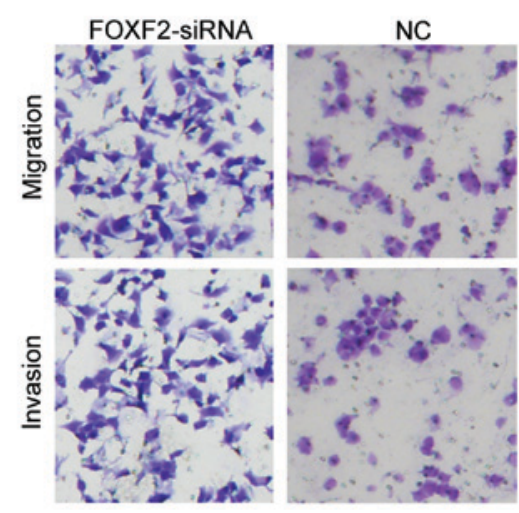

Figure 3. miR-182 downregulates FOXF2 by directly targeting its 3'UTR and regulates EMT. (A) The putative binding site of miR-182 in the 3'UTR of FOXF2. Mutant was generated in the 3'UTR of FOXF2, named as MT. (B) Analysis of luciferase activity. MCF-7 and MDA-MB-231 cells were cotranfected with miR-182 or miR-control, and FOXF2 3'UTR WT or MT. Firefly luciferase activity was normalized to Renilla luciferase activity. The data are from at least three independent experiments. "P<0.05. (C) Western blot analysis of EMT and FOXF2 protein levels in MCF-7 and MDA-MB-231 cell lines. (D) RNA specific to FOXF2 effects on MDA-MB-231 cell invasion and migration. miR, microRNA; FOX, forkhead-box (F2); EMT, epithelial-mesenchymal transition; MT, mutant-type; WT, wild-type; 3'UTR, 3'-untranslated region.

confirmed by qRT-PCR (Fig. 2A). The effects of miR-182 on the cell proliferation are shown in Fig. $2 \mathrm{~B}$ and $\mathrm{C}$ as determined by MTT assay. The cell growth curves showed that ectopic expression of miR-182 significantly promoted the proliferation of MCF-7 and MDA-MB-231 cells, indicating miR-182 promoted cell proliferation of TNBC. The results of migration and invasion from Transwell assay are shown in Fig. 2D. The overexpression of miR-182 significantly enhanced migration and invasion in both malignant (MCF-7, MDA-MB-231) cell lines. Therefore, the results suggested that miR-182 could promote proliferation, migration and invasion of TNBC cells in vitro.

miR-182 promotes TNBC metastasis in vivo. To monitor the effect of miR-182 overexpression on the growth and metastasis of in vivo, we injected the MDA-MB-231 cells transfected with miR-182 or miR-control into the tail vein of nude mice ( $\mathrm{n}=10$ for each group). We found that tumor volumes in MDA-MB-231/miR-182 mimic group were larger than NC groups within 4 weeks (Fig. 2E). In Fig. 2F, the mice with miR-182 overexpression tumors demonstrated an approximately six-fold increase in the number of metastatic lung nodules compared with NC group. These observations demonstrated that miR-182 expression drives tumor growth and metastasis in TNBC, thereby functioning as a potential metastatic miRNA.
FOXF2 is a direct target of miR-182. We identified FOXF2 as predicted target gene of miR-182 from TargetScan and miRanda database. The putative binding site for miR-182 was found in 688-695 bp of FOXF2 3'UTR (Fig. 3A). To confirm the prediction, a luciferase reporter assay was performed in MCF-7 and MAD-MB-231 cells. FOXF2 3'UTR WT or MT was cloned into pmiRGLO vector based on luciferase reporter assay, which were then transfected into cells with miR-182 mimic or miR-control. The relative luciferase activity was significantly decreased in cells cotransfected with WT 3'UTR of FOXF2 and miR-182 mimic compared with negative control cells. However, the effect was abolished when MT 3'UTR was cotransfected with miR-182 mimic (Fig. 3B).

Furthermore, we examined the expression of FOXF2 affected by miR-182. The silence of miR-182 significantly increased endogenous FOXF2 expression at the protein levels in both MCF-7 and MAD-MB-231 cells $(\mathrm{P}<0.05)$ as confirmed by western blot analysis (Fig. 3C). Furthermore, we detected the specific effects of siRNA specific to FOXF2 on the cell proliferation and metastasis of TNBC cells by Transwell assay. The result showed that FOXF2 inhibits MDA-MB-231 cells invasion and migration (Fig. 3D). Besides, we detected the influence of miR-182 on EMT progress in both cell types. We found that miR-182 inhibitor increased the expression level of epithelial marker E-cadherin and decreased the levels of mesenchymal markers (Fig. 3C). It is probably that the 
miR-182 promoting migration and invasion was performed by activation of EMT program in TNBC cells.

Taken together, these results indicated that FOXF2 was a direct downstream target of miR-182 and EMT progression was inactivated by the miR-182 inhibitor.

\section{Discussion}

TNBC refers to a specific subtype of BC that lacks expression of the ER, PR and HER2 (27). Patients with TNBC have an increased likelihood of metastasis and distant recurrence compared to patients with other BCs (28). miRNAs are critical regulators of gene expression and their dysregulation has been reported to be closely related to tumorigenesis and cancer metastasis (29-31). Therefore, there is a major unmet need to better understand the molecular basis of this type of BC as well as develop new therapeutic strategies against it.

Although miR-182 is showed to promote apoptosis and to inhibit the proliferation of lung cancer cells as a tumor suppressor (32), it has been revealed to be an oncogene in most malignancies, such as prostate cancer (24), medulloblastoma (33), melanoma (34), and glioma (35). Given miR-182 acts as an oncogene in various cancers and a valuable marker for prognosis of TNBC, we validated miR-182 expression in TNBC cell lines and tissues by qRT-PCR. The results showed that the miR-182 expression levels in the TNBC cells and tissues are significantly higher than those in the normal cells and tissues, which was consistent with previous reports $(8,36)$. Furthermore, we observed the depletion of miR-182 resulted in E-cadherin increase (Fig. 3C). The increase of E-cadherin expression from adherent junction leads to the inhibitor of $\mathrm{N}$-catenin into the cytoplasm during EMT progression, which reveal miR-182 activating EMT program in TNBC cells. The above thus indicated that miR-182 may act as a cancer promoter in TNBC.

It is well known that FOXF2 may act as a novel EMT-suppressing factor to induce apoptosis regulation, metastasis, invasion and poor prognosis in divergent cancer types (25,37-39). Previous reports have revealed a variety of embryonic and mesenchymal transcriptional factors function as EMT activators in BC, including FOXC2 (40) and FOXQ1 (41). Wang et al uncovered that FOXF2 was a novel EMT-suppressing transcription factor in basal-like breast cells, whose inhibitor enhanced the metastatic ability by inducing an EMT phenotype (25). In our study, qRT-PCR analysis showed significantly lower mRNA levels of FOXF2 in TNBC, compared with normal tissue (Fig. 1C) and siRNA specific to FOXF2 revealed FOXF2 inhibits cell invasion and migration (Fig. 3D), thus indicating FOXF2 may act as a suppressor in TNBC.

In the present study, we applied both western blot analysis and luciferase reporter assay to identify FOXF2 as a direct and functional target of miR-182 in TNBC. Other reports show FOXF2 was regulated by miR-301 (42) and miR-183-96182 cluster (43). FOXF2 decreased Wnt5a signaling pathway to promote angiogenesis and cell survival (44). Hirata et al reported that FOXF2 mRNA has two potential binding sites for miR-182-5p within its 3'UTR (24). In this study, we demonstrated that FOXF2 was downregulated by miR-182 by targeting its 3'UTR in TNBC cells.
In conclusion, we revealed that miR-182 can significantly promote TNBC cell proliferation, invasion and metastasis. FOXF2 was identified as a direct and functional target of miR-182. The newly identified miR-182/FOXF2 axis provides new insight into the pathogenesis of TNBC and represents a potential therapeutic target for TNBC.

\section{References}

1. Honkoop AH, van Diest PJ, de Jong JS, Linn SC, Giaccone G, Hoekman K, Wagstaff J and Pinedo HM: Prognostic role of clinical, pathological and biological characteristics in patients with locally advanced breast cancer. Br J Cancer 77: 621-626, 1998.

2. Medimegh I, Omrane I, Privat M, Uhrhummer N, Ayari H, Belaiba F, Benayed F, Benromdhan K, Mader S, Bignon IJ, et al: MicroRNAs expression in triple negative vs non triple negative breast cancer in Tunisia: Interaction with clinical outcome. PLoS One 9: e111877, 2014.

3. Rakha EA, Elsheikh SE, Aleskandarany MA, Habashi HO, Green AR, Powe DG, El-Sayed ME, Benhasouna A, Brunet JS, Akslen LA, et al: Triple-negative breast cancer: Distinguishing between basal and nonbasal subtypes. Clin Cancer Res 15: 2302-2310, 2009.

4. Ishikawa T, Shimizu D, Kito A, Ota I, Sasaki T, Tanabe M, Yamada A, Arioka H, Shimizu S, Wakasugi J, et al: Breast cancer manifested by hematologic disorders. J Thorac Dis 4: 650-654, 2012

5. Fausto P and Barni S: Benefit of tamoxifen in estrogen receptor positive DCIS of the breast. Gland Surg 1: 3-4, 2012.

6. Bagaria SP, Ray PS, Sim MS, Ye X, Shamonki JM, Cui X and Giuliano AE: Personalizing breast cancer staging by the inclusion of ER, PR, and HER2. JAMA Surg 149: 125-129, 2014.

7. Andrés R, Pajares I, Balmaña J, Llort G, Ramón Y Cajal T, Chirivella I, Aguirre E, Robles L, Lastra E, Pérez-Segura P, et al: Association of BRCA1 germline mutations in young onset triple-negative breast cancer (TNBC). Clin Transl Oncol 16: 280-284, 2014.

8. Liu H, Wang Y, Li X, Zhang YJ, Li J, Zheng YQ, Liu M, Song X and Li XR: Expression and regulatory function of miRNA-182 in triple-negative breast cancer cells through its targeting of profilin 1. Tumour Biol 34: 1713-1722, 2013.

9. Cheang MC, Voduc D, Bajdik C, Leung S, McKinney S, Chia SK, Perou CM and Nielsen TO: Basal-like breast cancer defined by five biomarkers has superior prognostic value than triple-negative phenotype. Clin Cancer Res 14: 1368-1376, 2008.

10. Gelmon K, Dent R, Mackey JR, Laing K, McLeod D and Verma S: Targeting triple-negative breast cancer: Optimising therapeutic outcomes. Ann Oncol 23: 2223-2234, 2012.

11. Di Leva $\mathrm{G}$ and Croce CM: The role of microRNAs in the tumorigenesis of ovarian cancer. Front Oncol 3: 153, 2013.

12. Korpal M, Ell BJ, Buffa FM, Ibrahim T, Blanco MA, Celià-Terrassa T, Mercatali L, Khan Z, Goodarzi H, Hua Y, et al: Direct targeting of Sec23a by miR-200s influences cancer cell secretome and promotes metastatic colonization. Nat Med 17: 1101-1108, 2011.

13. Dong R, Liu X, Zhang Q, Jiang Z, Li Y, Wei Y, Li Y, Yang Q, Liu J, Wei JJ, et al: miR-145 inhibits tumor growth and metastasis by targeting metadherin in high-grade serous ovarian carcinoma. Oncotarget 5: 10816-10829, 2014.

14. Link A, Kupcinskas J, Wex T and Malfertheiner P: Macro-role of microRNA in gastric cancer. Dig Dis 30: 255-267, 2012.

15. Du L and Pertsemlidis A: microRNA regulation of cell viability and drug sensitivity in lung cancer. Expert Opin Biol Ther 12: 1221-1239, 2012.

16. Wall NR: Colorectal cancer screening using protected microRNAs. J Gastrointest Oncol 2: 206-207, 2011.

17. Saus E, Soria V, Escaramís G, Vivarelli F, Crespo JM, Kagerbauer B, Menchón JM, Urretavizcaya M, Gratacòs M and Estivill X: Genetic variants and abnormal processing of pre-miR-182, a circadian clock modulator, in major depression patients with late insomnia. Hum Mol Genet 19: 4017-4025, 2010

18. Moskwa P, Buffa FM, Pan Y, Panchakshari R, Gottipati P, Muschel RJ, Beech J, Kulshrestha R, Abdelmohsen K, Weinstock DM, et al: miR-182-mediated down-regulation of BRCA1 impacts DNA repair and sensitivity to PARP inhibitors. Mol Cell 41: 210-220, 2011 
19. Chiang $\mathrm{CH}$, Hou MF and Hung WC: Up-regulation of miR-182 by $\beta$-catenin in breast cancer increases tumorigenicity and invasiveness by targeting the matrix metalloproteinase inhibitor RECK. Biochim Biophys Acta 1830: 3067-3076, 2013

20. Guttilla IK and White BA: Coordinate regulation of FOXO1 by miR-27a, miR-96 and miR-182 in breast cancer cells. J Biol Chem 284: 23204-23216, 2009.

21. Li P, Sheng C, Huang L, Zhang H, Huang L, Cheng Z and Zhu Q miR-183/-96/-182 cluster is upregulated in most breast cancers and increases cell proliferation and migration. Breast Cancer Res 16: 473, 2014.

22. Aitola M, Carlsson P, Mahlapuu M, Enerbäck S and PeltoHuikko M: Forkhead transcription factor FoxF2 is expressed in mesodermal tissues involved in epithelio-mesenchymal interactions. Dev Dyn 218: 136-149, 2000.

23. Myatt SS and Lam EW: The emerging roles of forkhead box (Fox) proteins in cancer. Nat Rev Cancer 7: 847-859, 2007.

24. Hirata H, Ueno K, Shahryari V, Deng G, Tanaka Y, Tabatabai ZL, Hinoda Y and Dahiya R: microRNA-182-5p promotes cell invasion and proliferation by down regulating FOXF2, RECK and MTSS1 genes in human prostate cancer. PLoS One 8: e55502, 2013.

25. Wang QS, Kong PZ, Li XQ, Yang F and Feng YM: FOXF2 deficiency promotes epithelial-mesenchymal transition and metastasis of basal-like breast cancer. Breast Cancer Res 17: 30, 2015.

26. Pandey V, Perry JK, Mohankumar KM, Kong XJ, Liu SM, Wu ZS, Mitchell MD, Zhu T and Lobie PE: Autocrine human growth hormone stimulates oncogenicity of endometrial carcinoma cells. Endocrinology 149: 3909-3919, 2008.

27. Kim YJ, Choi JS, Seo J, Song JY, Lee SE, Kwon MJ, Kwon MJ, Kundu J, Jung K, Oh E, et al: MET is a potential target for use in combination therapy with EGFR inhibition in triple-negative/basal-like breast cancer. Int J Cancer 134 2424-2436, 2014.

28. Dent R, Trudeau M, Pritchard KI, Hanna WM, Kahn HK, Sawka CA, Lickley LA, Rawlinson E, Sun P and Narod SA: Triple-negative breast cancer: Clinical features and patterns of recurrence. Clin Cancer Res 13: 4429-4434, 2007.

29. Garzon R, Calin GA and Croce CM: MicroRNAs in cancer. Annu Rev Med 60: 167-179, 2009.

30. Kasinski AL and Slack FJ: Epigenetics and genetics. MicroRNAs en route to the clinic: Progress in validating and targeting microRNAs for cancer therapy. Nat Rev Cancer 11: 849-864, 2011

31. Pencheva $\mathrm{N}$ and Tavazoie SF: Control of metastatic progression by microRNA regulatory networks. Nat Cell Biol 15: 546-554, 2013.

32. Zhang L, Liu T, Huang Y and Liu J: microRNA-182 inhibits the proliferation and invasion of human lung adenocarcinoma cells through its effect on human cortical actin-associated protein. Int J Mol Med 28: 381-388, 2011.
33. Weeraratne SD, Amani V, Teider N, Pierre-Francois J, Winter D, Kye MJ, Sengupta S, Archer T, Remke M, Bai AH, et al: Pleiotropic effects of miR-183 96 182 converge to regulate cell survival, proliferation and migration in medulloblastoma. Acta Neuropathol 123: 539-552, 2012.

34. Segura MF, Hanniford D, Menendez S, Reavie L, Zou X, Alvarez-Diaz S, Zakrzewski J, Blochin E, Rose A, Bogunovic D, et al: Aberrant miR-182 expression promotes melanoma metastasis by repressing FOXO3 and microphthalmiaassociated transcription factor. Proc Natl Acad Sci USA 106: 1814-1819, 2009.

35. Song L, Liu L, Wu Z, Li Y, Ying Z, Lin C, Wu J, Hu B, Cheng SY, Li M, et al: TGF- $\beta$ induces miR-182 to sustain NF- $\kappa$ B activation in glioma subsets. J Clin Invest 122: 3563-3578, 2012.

36. Zhang W, Qian P, Zhang X, Zhang M, Wang H, Wu M, Kong X, Tan S, Ding K, Perry JK, et al: Autocrine/paracrine human growth hormone-stimulated MicroRNA 96-182-183. Cluster promotes epithelial-mesenchymal transition and invasion in breast cancer. J Biol Chem 290: 13812-13829, 2015.

37. Kong PZ, Yang F, Li L, Li XQ and Feng YM: Decreased FOXF2 mRNA expression indicates early-onset metastasis and poor prognosis for breast cancer patients with histological grade II tumor. PLoS One 8: e61591, 2013.

38. Lam EW, Brosens JJ, Gomes AR and Koo CY: Forkhead box proteins: Tuning forks for transcriptional harmony. Nat Rev Cancer 13: 482-495, 2013.

39. Wang Z, Liu P, Inuzuka H and Wei W: Roles of F-box proteins in cancer. Nat Rev Cancer 14: 233-247, 2014.

40. Mani SA, Yang J, Brooks M, Schwaninger G, Zhou A, Miura N, Kutok JL, Hartwell K, Richardson AL and Weinberg RA: Mesenchyme Forkhead 1 (FOXC2) plays a key role in metastasis and is associated with aggressive basal-like breast cancers. Proc Natl Acad Sci USA 104: 10069-10074, 2007.

41. Qiao Y, Jiang X, Lee ST, Karuturi RK, Hooi SC and Yu Q: FOXQ1 regulates epithelial-mesenchymal transition in human cancers. Cancer Res 71: 3076-3086, 2011.

42. Shi W, Gerster K, Alajez NM, Tsang J, Waldron L, Pintilie M, Hui AB, Sykes J, P'ng C, Miller N, et al: MicroRNA-301 mediates proliferation and invasion in human breast cancer. Cancer Res 71: 2926-2937, 2011.

43. Kundu ST, Byers LA, Peng DH, Roybal JD, Diao L, Wang J, Tong P, Creighton CJ and Gibbons DL: The miR-200 family and the miR-183 96 182 cluster target Foxf2 to inhibit invasion and metastasis in lung cancers. Oncogene 35: 173-186, 2016.

44. Yamamoto H, Oue N, Sato A, Hasegawa Y, Yamamoto H, Matsubara A, Yasui W and Kikuchi A: Wnt5a signaling is involved in the aggressiveness of prostate cancer and expression of metalloproteinase. Oncogene 29: 2036-2046, 2010. 